\title{
LASER CladDing IN THE TOOLING INDUSTRY
}

\section{LESTAN, Z.; BREZOCNIK, M.; MILFELNER, M. \& BALIC, J.}

Abstract: High tensile forming materials used in the automotive industry are extremely aggressive for shaping and cutting tools, so new materials and technologies in the tooling industry are required in order to keep the production cost as low as possible. In this paper we present an innovative use of the LENS technology in the tooling industry. Two practical examples are presented: in the first one the LENS technology is used as a fast and effective way for modification of deep drawing tools in the developing process. In the second example an innovative way for cutting tools is presented. Instead that the whole tool is made of high quality material, only the cutting edge, which is subjected to high compressive forces, is made of cutting material with laser cladding. This not only reduces production costs, but also extends the tool life and the tool is easy to repair.

Key words: laser cladding, tooling, deep drawing
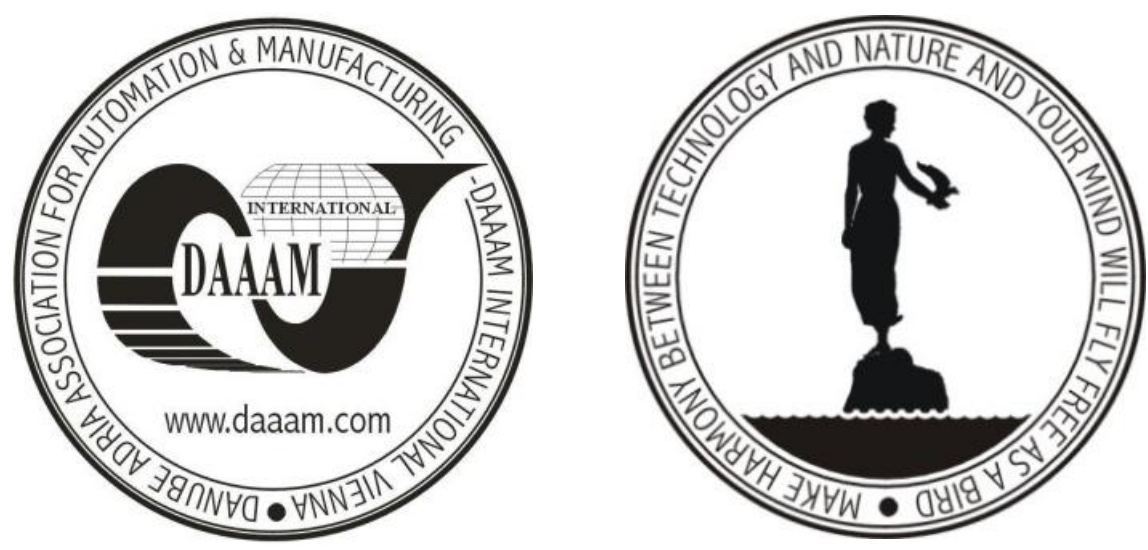

Authors' data: B.Sc. Lestan, Z[oran]*; D.Sc. Brezocnik, M[iran]**; D.Sc. Milfelner, M[atjaz $]^{*}$; D.Sc. Balic, J[oze ${ }^{* *}$, *EMO-Orodjarna d.o.o., Bezigrajska cesta 10, 3000 Celje, Slovenia, **University of Maribor; Faculty of Mechanical Engineering, Smetanova 17, 2000 Maribor, Slovenia, zoran.lestan@emo.orodjarna.si, mbrezocnik@uni-mb.si,matjaz.milfelner@emo-orodjarna.si,joze.balic@uni-mb.si

This Publication has to be referred as: Lestan, Z[oran]; Brezocnik, M[iran]; Milfelner, M[atjaz] \& Balic, J[oze] (2012). Laser Cladding in the Tooling Industry, Chapter 04 in DAAAM International Scientific Book 2012, pp. 045-052, B. Katalinic (Ed.), Published by DAAAM International, ISBN 978-3-901509-86-5, ISSN 17269687, Vienna, Austria

DOI: 10.2507/daaam.scibook.2012.04 
Lestan, Z.; Brezocnik, M.; Milfelner, M. \& Balic, J.: Laser Cladding in the Tooling...

\section{Introduction}

Deep drawing is one of the most common manufacturing processes in the automotive industry. Almost all parts of the car body are made with this procedure. Because the geometrical tolerance for these parts are tight and the drawing tools expensive, accurate planning of the drawing tools is essential. Because new forming materials with elevated tensile strength are nowadays also used in the car body, engineers are subjected to new challenges. The high strength forming materials are extremely aggressive for shaping and cutting tools, so new materials and technologies in the tooling industry are required. The second problem is the springback effect upon unloading after the forming stage, the product springs back due to internal stresses. For large parts such as car body panels, these deformations can be up to several millimetres. This forces the manufacturers to manually correct the deep drawing tools so that the effect caused by springback is compensated. This can be an expensive and time consuming procedure. The product must be measured, CAD data modified and tools reworked. FEM simulations are usually used in this optimization loop and help to keep the number of iterations to a minimum (Lingbeek et al. 2005). The tools are usually modified with adding or removing material from the surface of the tool. Removing the material is usually not a problem, but adding is. Traditionally this was done with TIG welding, but the problem is that it is a time consuming process. In order to improve productivity, laser cladding can be used for this matter. A comparison between diode laser and TIG cladding (Xu et al. 2006) showed that the dilution is much lower in the case of diode laser cladding. A much smaller heat affected zone was also achieved and the cladding layer had a higher hardness.

For coating purposes, in order to make the surface of the tool more wear resistant, special coating materials are used which often contain carbides. The thickness of the coating rarely exceeds $1 \mathrm{~mm}$, because the carbide containing material tends to crack if the coating is too thick (Bandyopadhyay et at. 2007). Because greater thicknesses are also required, puffer material is used. The puffer is deposited first and only the top layer is made from wear resistant material. This way it is possible to achieve the required clad thickness with the desired mechanical properties. Puffer layers are also used on cutting edges in order to prevent the impress of the cutting edge when softer material is used as base material. This is very useful because the whole cutting tool does not have to be made of quality material, which significantly reduces the costs.

Differences in material properties cause residual stresses and may lead to peeling or crack formation. Many coating materials have a very small processing window, so it is important to find the appropriate parameters. Researchers have reported to successfully deposited various coating materials on different components, also on cast iron (Ocelik et al. 2007, Lestan et al. 2010). A Nd:YAG laser has been used to explore the possibility to repair dies with vanadium-carbide tool steels (Leunda et al. 2011). Because of their high hardness and good wear resistance carbide powders are also used as coating material. Researchers are investigating different mixtures of carbides and process parameters in order to enhance mechanical properties and to achieve a better control of the microstructures (Srivatsan et al.). 
The LENS technology is characterized by the use of low power lasers which produce a very small heat affected zone. In typical applications the laser power is only 300-500 W. At this scale it is important to understand the entire thermal behaviour of the process. Many studies on thin wall structures supported by numerical simulations have already been reported (Bontha et al. 2006, Ye et al. 2006).

In this paper we present the LENS technology in the tooling industry as a tool for repairing, modification and coating application. The whole process is presented, from 3D modelling to the actual deposition with examples from the industry. Although the LENS technology is primary used for building fully functional 3D parts, the research in this paper was focused on the cladding procedure. The first example presents a modification of a deep drawing tool and the second is showing the development of a cutting edge on a cutting die. Previous cladding tests have been made in order to produce crack free coatings on the actual parts.

\section{How LENS works}

There are several technologies on the market which can produce components from metal powders. The technologies are very similar and differ just in detail such as laser type, powder delivery system, protection from oxidation, etc. Deposition of material with the LENS technology is done with a special laser head which is shown on Figure 1. In the laser head is a lens which focuses the laser beam on the surface where it creates a small molten pool. In the molten pool powder is blown with the help of a carrier gas.

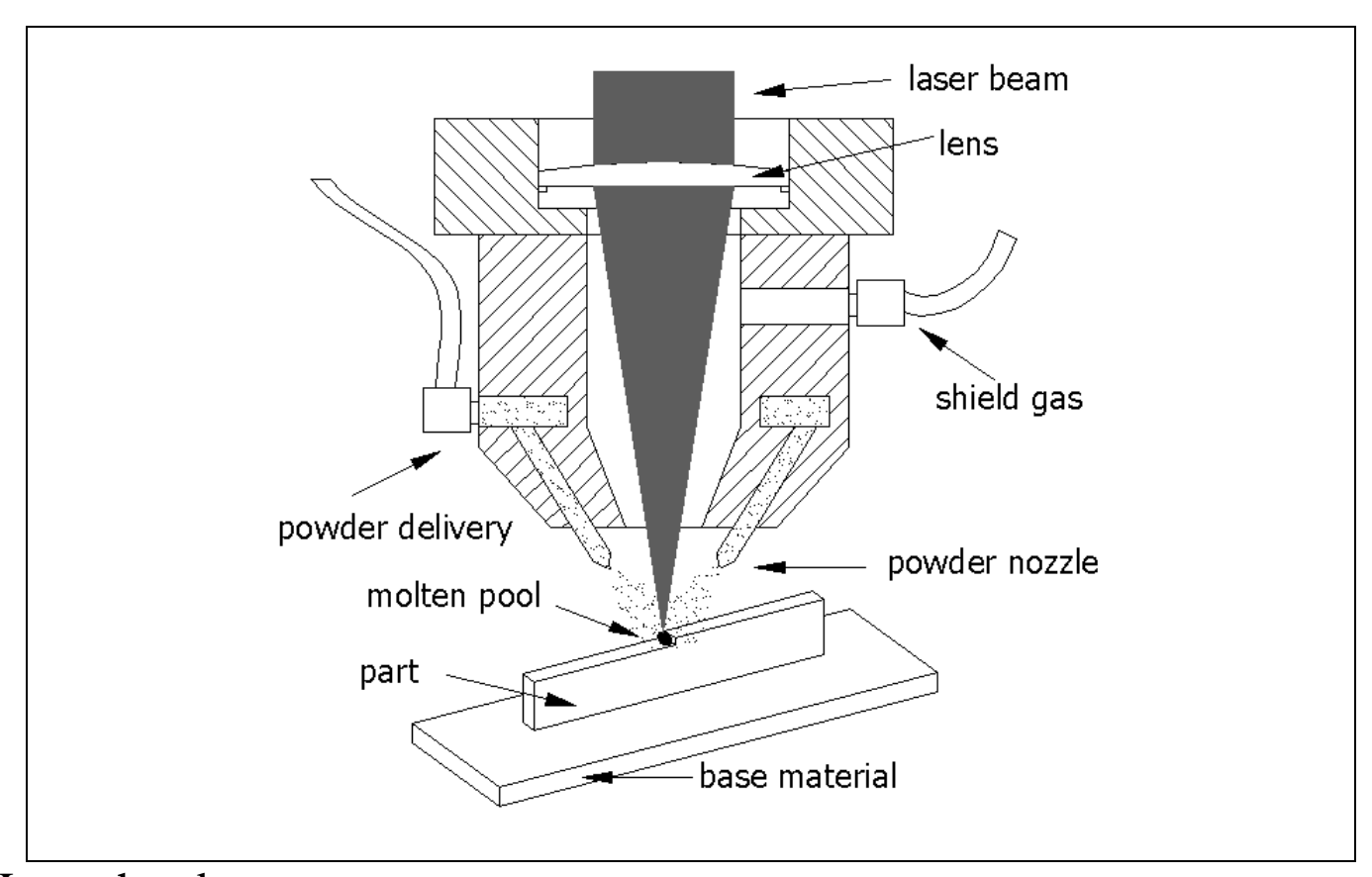

Fig. 1. Laser head

Some of the powder bounces of the surface and some is caught by the molten pool. The powder melts quickly when entering the molten pool and solidifies when 
the laser head moves away. The solidification is very quick because the heat is rapidly conducted away from the melt pool. The material is deposited in a shape of a line, which dimensions are set by the process parameters. One layer is made of a number of lines of deposited material. When one layer is finished, the laser head moves up for one layer thickness and begins building the next layer. This procedure continues until the whole part is completed. Because the material in the process is melted, oxidation must be prevented. That is why the process takes place in an airtight chamber filled with an inert gas such as nitrogen or argon.

\section{Cladding procedure}

All laser cladding technologies including LENS adopt the same basic approach when it comes to actual cladding procedure. There are five steps needed to produce a quality clad. These steps are: 3D modelling, data conversion, checking and preparing, building and post processing.

\subsection{D modelling}

The first step in the process chain is modelling. For this step modelling software is needed, or the model can be created directly on the machine via the "teach \& learn" procedure. This in mostly used when repairing non complicated parts. When modelling a part it is necessary to take into account the limitations of the machines on which the part will be made. Because it is not possible to use support material in the LENS technology, only overhangs up to $30^{\circ}$ are possible to build with a 3 axis movement.

\subsection{Data conversion}

In this step the 3D model has to be converted in a file that can be read by the machine software. In our case the model is converted into a .stl file. This step is relative simple, because all modern modelling software enables to save the models in various formats.

\subsection{Checking and preparing}

Sometimes errors are made while the 3D model is converted into the .stl model. The most common errors are unwanted holes in the surface of the model which have to be patched. Before the next step the model has to be checked and repaired with appropriate software. When we are satisfied with the model it is time to slice it in layers. In the slicing program we have to specify slicing parameters such as layer thickness, hatch shrink, hatch distance, hatch angles, etc. A layer of a slice file is shown on Figure 2. Each line on the layer presents a path of the laser. Values for the slicing parameters must be chosen wisely because they have a great affect on the cladding. If we want that the foreseen layer thickness will be equal to the actual deposited thickness, the hatch distance must be just right. Of course it is possible to affect the deposition during building with changing of the laser power or translation speed of the laser head. After the appropriate values are given, the program slices the 
model and saves it in a .sli file. Before we can start cladding the part, the .sli file has to be converted into a G - code or a DMC code. This is done with the control program of the LENS machine. In this step we have to specify some additional parameters such as acceleration and deceleration for individual axes, building resolution, number of the powder hopper from which the powder will be delivered, mass flow of the powder, etc.

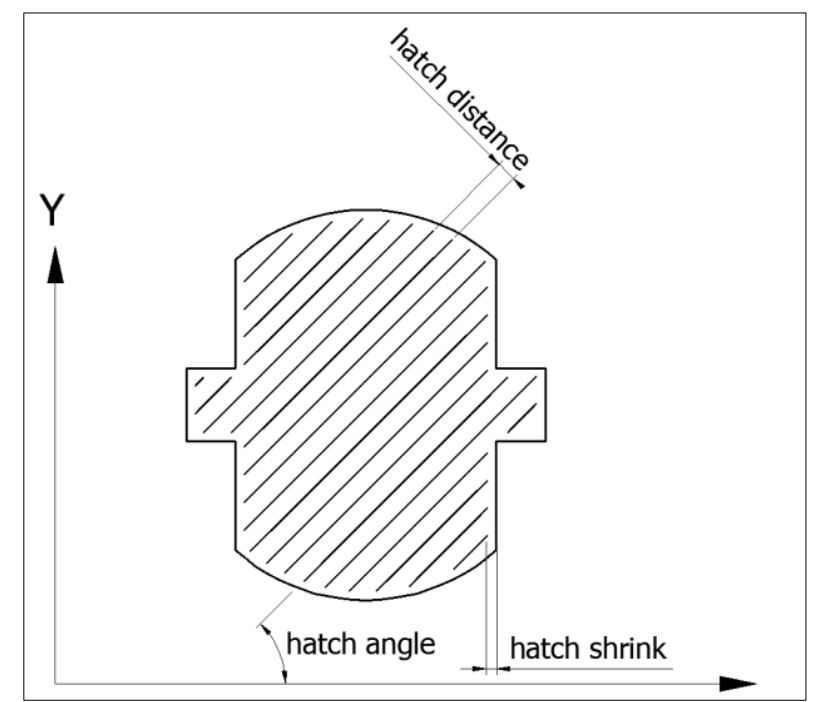

Fig. 2. One layer of a slice file

\subsection{Cladding}

The laser head must first be taken to the start position and lowered on the focal distance from the base material. When the process is started the operator must carefully observe the deposition of the material and adjust the process parameters so that the building of the part goes as planned. The trick is that the focal distance between the laser head and the part is maintained all the time. The operator must adjust the parameters so that the layer height being deposited is equal to the distance which the laser head moves up when a layer is finished. The distance between the laser head and the part is maintained by changing laser power, powder mass flow or translation speed of the laser head. Decreasing the laser power or the mass flow will result less material deposition; on the other hand decreasing the translation speed will increase the layer thickness.

\subsection{Post processing}

Because the surface of the clad is relatively rough, it needs to be post processed to achieve the required tolerance and a smooth surface. This is usually done with milling or grinding. The rough surface is sometimes welcome, usually when producing implants.

\section{Modification of a deep drawing tool}

As mentioned before, in the development process of deep drawing tools, there is often the need of tool modification due to the springback effect. Figure 3 presents 
such a modification. The geometry of a tool segment is being modified with adding material on the surface of the tool. The tool is made of a cold work steel $\mathrm{X} 153 \mathrm{CrMoV} 12$. Because on some areas of the tool the clad was up to $3 \mathrm{~mm}$ thick, the tool had to be preheated in a furnace in order to avoid cracks. The preheating temperature was $300^{\circ} \mathrm{C}$. The $3 \mathrm{D}$ model of the clad was designed with excess material so the part could be post processed with milling.

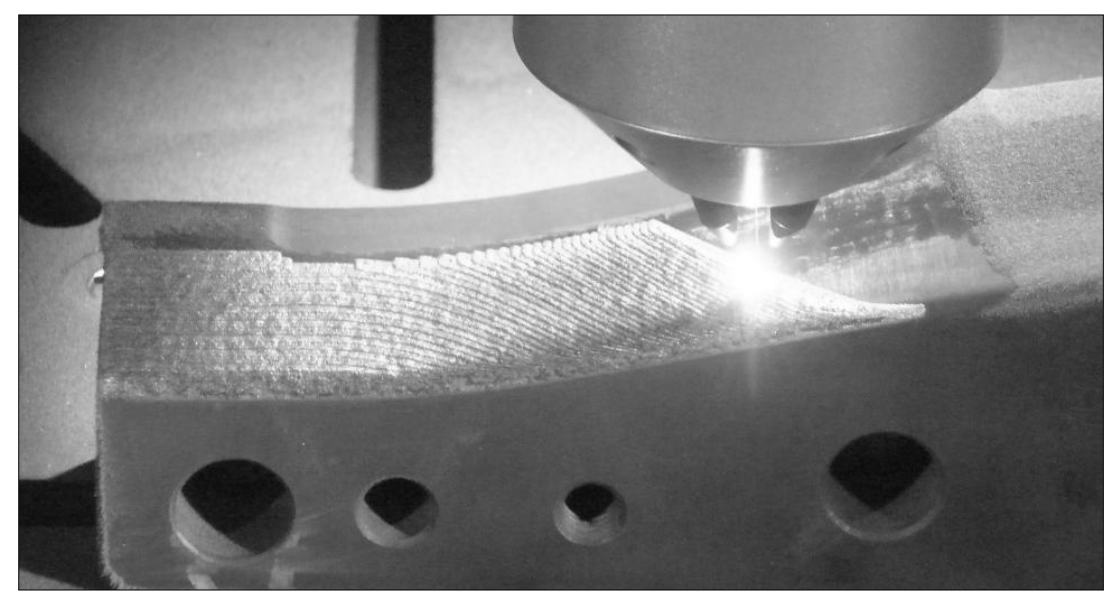

Fig. 3. Cladding of a deep drawing tool

The cladding was done with a LENS 850-R machine which uses a $1 \mathrm{~kW}$ ytterbium fibre laser. X40CrMoV51 powder was used as cladding material and argon as shielding gas. The oxygen level during the cladding procedure did not exceed 7 ppm (parts per million). The hardness of the clad layer was measured with a portable measuring device Krauthamer MIC 20. The cladding had an average hardness of 51 $\mathrm{HRc}$ which is an excellent value for this material.

\section{Making a cutting edge}

Cutting dies are very important in the automotive industry and need to be manufactured with care and precision. Because of high strength forming materials, the cutting edges are even more subjected to failure. Figure 4 presents the contribution of compressive forces in the sheet metal shearing process. It can be seen that only a small area is subjected to compressive forces. It would therefore be irrational to produce the whole tool from high quality material. Figure 5 presents an innovative making of a cutting edge. The base material for the cutting tool was an inexpensive construction steel EN-S235JR. The first step was to make place for the cutting material (Figure 5, left image). Because the EN-S235JR is very soft steel, puffer was used. A $3 \mathrm{~mm}$ deep and $5 \mathrm{~mm}$ wide notch was made at the edge of the tool. Than the puffer material was deposited. For this purpose $316 \mathrm{~L}$ stainless steel was used. The cladding was also carried out on a LENS 850-R with argon as shielding gas. The average cladding height of the puffer was $2.8 \mathrm{~mm}$. To achieve an even thickness, the puffer was levelled to en end height of $2.6 \mathrm{~mm}$. The average hardness of the puffer was $31 \mathrm{HRc}$. After the puffer layer was levelled and the hardness was measured, the surface was sand blasted and prepared for the next step. 
As cutting material, HS6-5-2 was used. This is a molybdenum high speed tool steel with a very high resistance to wear, good toughness and cutting capability. Two layers of HS6-5-2 were deposited in order to achieve the required thickness (Figure 5, middle image). After the cladding procedure the tool was ground in order to achieve a smooth and even surface.

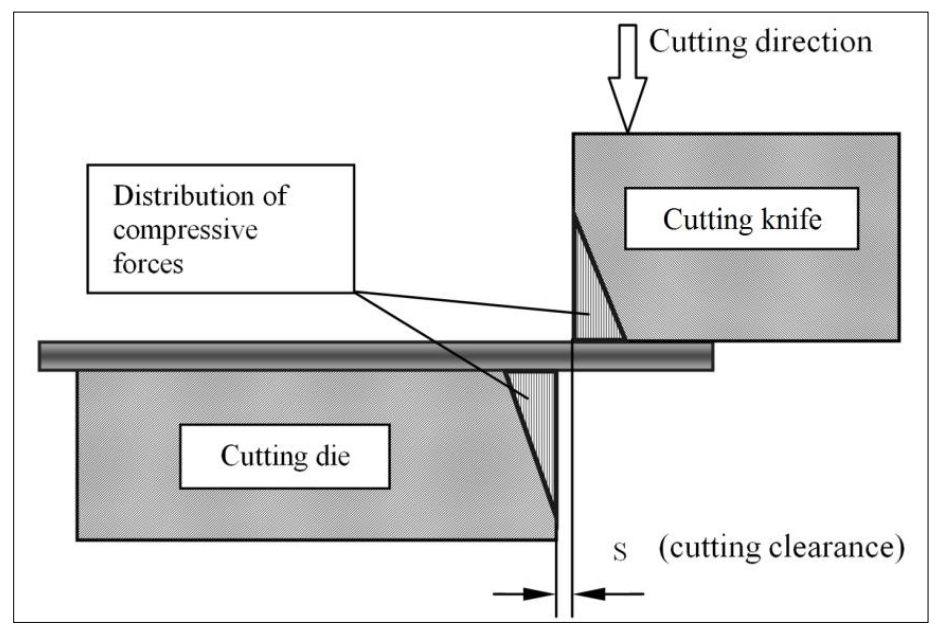

Fig. 4. Cladding of a deep drawing tool

The measuring device showed an average hardness of $62 \mathrm{HRc}$. The end product can be seen on Figure 5 (left image). The cutting edge appears a little darker than other material. The surface of the clad was inspected with an optical microscope and was crack free.

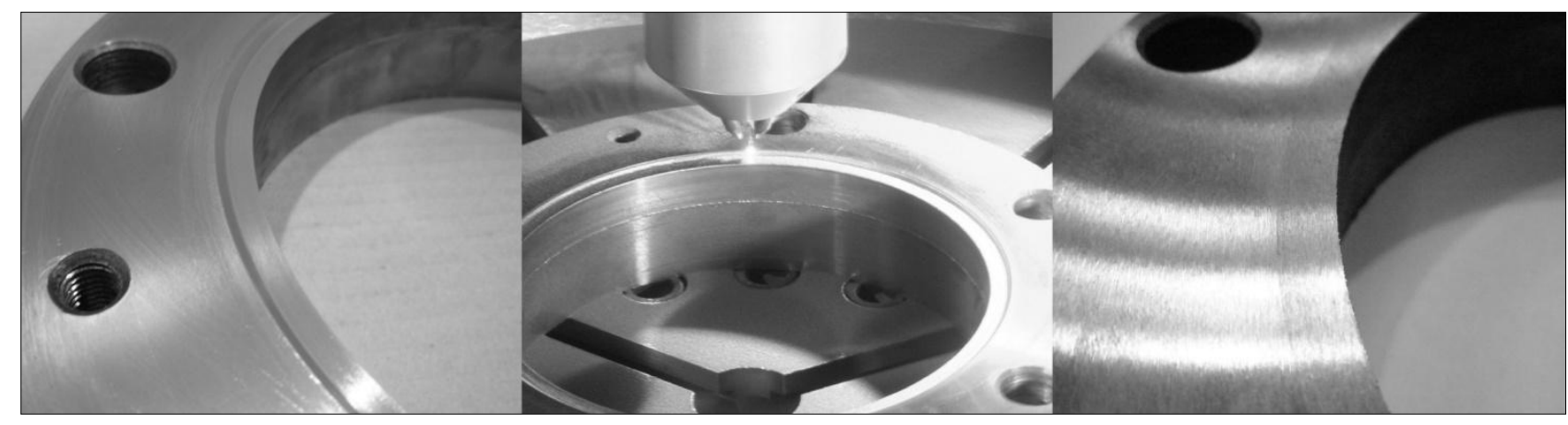

Fig. 5. Making a cutting edge

\section{Conclusions}

In this paper the LENS technology was shortly presented and two practical examples from the tooling industry were briefly described. Because new forming materials with elevated tensile strength have found their way also into the automotive and tooling industry, engineers have to use new technologies and procedures in order to satisfy the needs of the customers. The LENS technology has proven itself also in the automotive industry. Not only as a fast and effective way to repair or modify deep drawing tools, but also as a technique for producing cutting edges. Future research will be focused on efficiency and optimization of the cladding process. The next step 
Lestan, Z.; Brezocnik, M.; Milfelner, M. \& Balic, J.: Laser Cladding in the Tooling...

is the development of an adaptive control system for achieving a constant quality of the deposited material

\section{Acknowledgement}

The Research is partially funded by the European Social Fund. Invitations to tenders for the selection of the operations are carried out under the Operational Programme for Human Resources Development for 2007-2013, 1. development priority: Promoting entrepreneurship and adaptability, the priority guidelines 1.1: Experts and researchers for enterprises to remain competitive.

\section{References}

Lingbeek R., Huétink J., Ohnimus S., Petzoldt M., Weiher J. (2005). The development of a finite elements based springback compensation tool for sheet metal products. Journal of Materials Processing Technology, vol. 169, no. 1, pp. 115125, ISSN: 0924-0136

Xu G., Kutsuna M., Liu Z., Yamada K. (2006). Comparison between diode laser and TIG cladding of Co-based alloys on the SUS403 stainless steel. Surface and Coatings Technology, 201, 1138-1144, ISSN: 0257-8972

Bandyopadhyay P.P., Balla V.K., Bose S., Bandyopadhyay A. (2007). Compositionally graded aluminum oxide coatings on stainless steel using laser processing, Journal of the American Ceramic Society, 90, 1989-1991, ISSN: 1551-2916

Ocelík V., Oliveira U., M. Boer M., Hosson J.T.M. (2007). Thick Co-based coating on cast iron by side laser cladding: Analysis of processing conditions and coating properties, Surface and Coatings Technology, 201, 5875-5883, ISSN: 0257-8972

Lestan Z., Drstvenšek I., Milfelner M., Brezocnik M., Stepisnik S. (2010). Deposition of steel coatings using LENS technology. Annals of DAAAM for 2010 \& proceedings of the 21 st International DAAAM symposium "Intelligent manufacturing \& Automation: "Focus on interdisciplinary solutions", ISBN 978-3-901509-73-5, 20-23rd October, Zadar, Croatia, str. 795-796

Leunda J., Soriano C., Sanz C., Navas V.G. (2011). Laser Cladding of VanadiumCarbide Tool Steels for Die Repair, Physics Procedia, 12, 345-352, ISSN: 18753892

Srivatsan T.S., Guruprasad G., Black D., Petraroli M., Radhakrishnan R., Sudarshan T.S. (2006). Microstructural development and hardness of TiB2-B4C composite samples: Influence of consolidation temperature, Journal of Alloys and Compounds, 413, 63-72, ISSN: 0925-8388

Bontha S., Klingbeil N.W., Kobryn P.A., Fraser H.L. (2006). Thermal process maps for predicting solidification microstructure in laser fabrication of thin-wall structures, Journal of Materials Processing Technology, 178, 135-142, ISSN: 0924-0136

Ye R., Smugeresky J.E., Zheng B., Zhou Y., Lavernia E.J. (2006). Numerical modeling of the thermal behavior during the LENS ${ }^{\circledR}$ process, Materials Science and Engineering: A, 428, 47-53, ISSN: 0921-5093 